\title{
Claude Lefort e a escrita democrática
}

\author{
Claude Lefort and Democratic Writing
}

\section{Silvana de Souza Ramos Universidade de São Paulo | São Paulo | Brasil}

\section{RESUMO}

A questão da Modernidade está no centro da escrita de Claude Lefort. Se tantos autores o ajudam a pensá-la, se acontecimentos precisos, especialmente a Revolução Francesa, a trouxeram à luz, é preciso dizer que Maquiavel assume aí um papel crucial. $\mathrm{O}$ trabalho da obra maquiaveliana ensina que, entre a licença e a tirania, a Cidade livre se equilibra, não num ponto em que o poder possa se justificar de maneira definitiva, muito menos segundo uma boa ordem que aboliria o conflito e a desordem, ou que escaparia à possiblidade de suspensão temporária da própria Lei que a organiza simbolicamente. Marcada pela indeterminação, a Modernidade vista por Maquiavel ajuda a compreender a invenção democrática, isto é, a experiência do político que não se ancora numa identidade fixa seja do poder, seja da cidadania ou, ainda, do próprio corpo político. Nosso trabalho busca investigar o elo moderno entre essa experiência e a escrita democrática segundo a visão de Claude Lefort.

\section{PALAVRAS-CHAVE}

Claude Lefort; Maquiavel; Democracia; Escrita; Política.

\begin{abstract}
The question of Modernity is at the heart of Claude Lefort's writing. If so many authors help him to think it, if precise events, especially the French Revolution, brought it to light, it must be said that Machiavelli plays a crucial role there. The work of the Machiavellian work teaches that, between license and tyranny, the Free City is balanced, not at a point where power can be definitively justified, much less according to a good order that would abolish conflict and disorder, or which would escape the possibility of temporary suspension of the very Law that organizes it symbolically. Marked by indeterminacy, the Modernity seen by Machiavelli helps to understand the democratic invention, that is, the experience of the politics who is not anchored in a fixed identity either of power, of citizenship or even of the body politic itself. Our work seeks to investigate the modern link between this experience and the democratic writing according to the vision of Claude Lefort.
\end{abstract}

\section{KEY WORDS}

Claude Lefort; Machiavelli; Democracy; Writing; Politics. 


\section{A situação do filósofo}

Ao retomar, nos escritos sobre Merleau-Ponty, o debate sobre a situação do filósofo, Lefort lembra que a filosofia suscita receio e irritação quando apenas reconhece no que advém o que deveria acontecer de qualquer modo. Ao buscar a verdade, a escrita filosófica precisa dar sentido ao acontecimento para torná-lo legível. Essa tarefa pode levá-la a escamotear a originalidade deste, convertendo-o em necessidade e fazendo-o desaparecer enquanto expressão da ação humana. Esse possível desfecho, porém, não nos poderia fazer esquecer da exigência própria à filosofia: a de descobrir "a realidade do real" (Lefort, 1978, p. 60) que nos envolve. $\mathrm{O}$ acontecimento solicita o pensar porque não é simplesmente uma coisa que aparece no espaço, fato empírico inscrito no tempo segundo um encadeamento imediatamente visível e, por isso, facilmente narrável. Pelo contrário, o acontecimento "contém em si mesmo o tempo, imprime uma súbita generalidade a uma coleção de fatos independentes, irradia passado e futuro em todas as direçôes" (Ibid.) e, assim, dá novo sentido à história na qual se inscreve. Ao estabelecer uma relação de continuidade e de descontinuidade com o passado, o acontecimento nos espanta porque seu elo com o que o antecede não é evidente. Esse desconcerto não deve paralisar o filósofo: tocado pelo acontecimento, este será levado a pensar e a rearticular simbolicamente os dados de que dispõe para então descobrir, no interior da experiência, o próprio movimento da história.

Nestes termos, podemos dizer que o acontecimento tem algo de simbólico e de estruturante, pois cria um transtorno na forma aparente da experiência, desfazendo uma necessidade para produzir outra, obrigando-nos, assim, a reorganizar a textura do real. O filósofo tem de submeter-se, a cada vez, à prova do particular, tornar suas as questões de sua época para deixar-se conduzir por elas até as questôes últimas, o que o obriga a retomar temas antigos, tradicionais da filosofia. Está, assim, aberto ao acontecimento, mas, ao mesmo tempo, imerso numa determinada tradição de pensamento. No momento em que decide ignorá-la e descobrir a verdade apenas em sua experiência, a distância que toma em relação aos filósofos do passado se mostra ilusória, pois jamais se abstém de explorar a herança destes, uma vez que foi formado por ela. No momento em que pretende, ao contrário, libertar-se da contingência e fazer-se cego para o acontecimento, o filósofo se esquece daquilo que ele próprio toma da experiência, escamoteia o solo a partir de onde fala e escreve e ignora, assim, a situação que lhe permite ler os contornos da história. Esquece-se, sobretudo, de que seus predecessores não tiveram acesso à verdade a não ser porque seu próprio tempo lhes facilitava a entrada (Ibid., p. 63). Decerto, a linguagem e as ambições do filósofo são aquelas que o tempo desenha no horizonte do pensável, porém, tocado pelo acontecimento, ele não pode simplesmente fechar-se no circuito da tradição, pois precisa ler as brechas 
do real segundo a exigência de pensamento por elas imposta. Em suma, segundo Lefort, o filósofo precisa direcionar o olhar para a fecundidade do acontecimento para então rearticular a tradição herdada, movimento que o leva a desdobrar no presente as obras do passado.

\section{Maquiavel e a Modernidade}

Desenhada num tempo preciso, a escrita de Lefort traz à tona uma Modernidade marcada por dois acontecimentos cruciais. De um lado, a invenção democrática, regime derivado especialmente das revoluções do século xvıII, quando a guilhotina não só cortou a cabeça do monarca como também foi capaz de desfazer a projeção de unidade e de identidade da nação na imagem mística do corpo régio. De outro lado, o totalitarismo, em especial o modelo soviético stalinista, espécie nova de contrarrevolução que pôs abaixo as esperanças de emancipação da humanidade segundo uma visão estritamente econômica dos motores da história. Expressa por esses dois regimes, a Modernidade só se esclarece, porém, pelo contraste com outras épocas, o qual faz aparecer sua singularidade própria. Diversas são as fontes que permitem lê-la: as lições da antropologia, o propósito dos historiadores da Revolução Francesa, as intuições de Tocqueville e, em especial, a obra de Maquiavel, à medida que dá visibilidade à fissura do mundo monárquico sobre a ruína do qual se edificaram pouco a pouco os novos tempos. ${ }^{1}$

A questão da Modernidade está no centro da escrita de Lefort. Se tantos autores o ajudam a pensá-la, se acontecimentos precisos a trouxeram à luz, é preciso dizer que Maquiavel assume aí um papel crucial. O trabalho desta obra ensina que, entre a licença e a tirania, a Cidade livre se equilibra, não num ponto em que o poder possa se justificar de maneira definitiva, muito menos segundo uma boa ordem que aboliria o conflito e a desordem, ou que escaparia à possiblidade de suspensão da própria Lei que a organiza simbolicamente. Se a liberdade exige um regime cujas instituições não podem ser louvadas em si mesmas, cuja imagem do poder vacila segundo o fluxo das opiniōes, dos afetos e do juízo do povo, então o poder jamais estará a salvo do perigo de perder o frágil ponto de estabilidade dinâmica que o preserva da destituição. Ao mostrar que, na Modernidade, o poder aparece como um lugar vazio, Lefort aponta para essa fragilidade, antes encoberta pela força da imagem de unidade que enlaçava num só golpe o povo e o governante, uma vez que ela era capaz de realizar a mediação entre o humano e o divino, fazendo do segundo a fonte última de sustentação do poder. A perda da eficácia da imagem unitária enquanto elemento central de mediação entre o poder e a comunidade política joga a Cidade nos tempos modernos e abre a

I Sobre o assunto, cf. Poltier, I997, p. 8 e ss. 
possiblidade de uma nova rede de relações entre os homens. Rede conflituosa e diferenciada internamente, que costura no horizonte a face vacilante do poder ao mesmo tempo em que institui o campo democrático de luta por direitos responsável por resistir ao vicejo da opressão política.

É certo que Lefort não lê Maquiavel como um autor circunscrito à realidade histórica que daria sentido imediato à sua obra. Se o filósofo francês busca elementos da modernidade política no discurso de um autor do Renascimento italiano, anterior ao acontecimento que deu origem à invenção democrática e, mais tarde, ao que trouxe à cena o terror totalitário, é porque vislumbra naquela obra um juízo certeiro capaz de fitar o poder segundo sua forma de aparição no espaço público. Maquiavel percebe que o problema da política é o da construção de um espaço de visibilidade capaz de regular a vida dos homens. Por um lado, o florentino mostra que a aparência é constitutiva do político e, por outro, demonstra que o lugar do poder não pode ser ocupado por uma boa imagem: a política, impulsionada pelo desejo de liberdade, não é regida pelos ditames da moral porque as feições do poder são por definição oscilantes, já que neste caso nenhuma imagem tem força suficiente para fixar-lhe a aparência e garantir-lhe legitimidade de uma vez por todas. Ao desvendar a lógica de um poder que se realiza na exterioridade, Maquiavel privou-o da substância que lhe daria corpo, tornando-o apreensível em sua dimensão simbólica. Assim, ao compreender a lógica da aparência inerente ao campo político, o florentino tornou possível a leitura do lugar do vazio do poder para além das imagens que tentam em vão estabilizá-lo numa aparência definitiva. ${ }^{2}$

Essa revelação maquiaveliana ajuda-nos a melhor compreender por que Lefort situa a democracia, ou o regime da liberdade nos tempos modernos, entre duas formas historicamente determinadas, o Antigo Regime e o Estado totalitário, considerando como tais regimes lidam com a questão do poder e realizam, assim, a experiência do político. No Antigo Regime, o Estado devora o social ao transformá-lo num órgão do corpo régio, de forma que o poder, a lei e o saber são personificados por essa unidade. No totalitarismo, novamente o social e o Estado são soldados num corpo único e indiferenciado, o do Partido-Estado, cujos órgãos e células constituem a textura atomizada de uma sociedade engolida pelo poder; poder cuja cabeça figura um dos nomes modernos da unidade, o Egocrata. É importante salientar, contudo, que há uma diferença que separa o Antigo Regime do totalitarismo: enquanto o primeiro preserva a referência do poder à transcendência, uma vez que a monarquia encontra seu fundamento na lei divina, o segundo se configura como totalitário exatamente porque abole

2 Sobre o assunto, cf. Adverse, 2009, pp. 45-47. 
qualquer referência à exterioridade. ${ }^{3} \mathrm{Na}$ monarquia,

[O príncipe era] um mediador entre os homens e as instâncias transcendentes figuradas pela Justiça soberana e pela Razão soberana. Submetido à lei e estando acima das leis, condensava em seu corpo, ao mesmo tempo mortal e imortal, os princípios de geração e de ordem do reino. Seu poder indicava um polo incondicionado, extraprofano, ao mesmo tempo que inspirava, na sua pessoa, a garantia e a representação da unidade do reino. Ele via a si mesmo afigurar-se como um corpo, como uma unidade substancial, de tal maneira que a hierarquia de seus membros, a distinção entre as posições e as ordens, parecia residir em um fundamento incondicionado (Lefort, I99I, p. 32).

No totalitarismo, ao contrário, "o poder não aponta para um além do social: é um poder que reina como se nada houvesse externo a si, como se fosse sem limites" (Ibid., p. 28, trad. modificada). Assim, no totalitarismo, não há alteridade possível, tampouco a possibilidade de fomento dos conflitos internos, pois tudo e todos estão incorporados no e pelo poder. O contraditório só pode aparecer aí como inimigo do poder, ou do corpo político enquanto tal, jamais como seu interlocutor e esteio. A necessidade da constante profilaxia do corpo político é o resultado preciso dessa equação que não comporta divisões.

Diferenciando-se desses fantasmas de unidade, a invenção democrática surge como um acontecimento extraordinário, pois ela é a instituição do político como nova instituição do social pelo fenômeno da desincorporação do poder e de seu correlato, a própria sociedade, quando a imagem, a ideia e o nome da unidade perdem eficácia prática e simbólica. Na democracia, encontramos uma nova estrutura de relações mediadas pela desincorporação reiterada da soberania. É para esse fenômeno inédito que Lefort aponta quando mostra, por exemplo, que a liberdade de opinião - instituída como direito universal — não a transforma em propriedade privada, pelo contrário, essa reivindicação se ancora na defesa de uma nova liberdade de relaçóes. A partir das Declarações de direitos, a cada qual é dada a possibilidade de se dirigir aos outros, e de ouvi-los: eis que um espaço simbólico se institui, sem fronteiras definidas, subtraído a toda autoridade que pretenda regê-lo ou decidir sobre o que é ou não pensável, sobre o que é ou não dizível. Assim, a fala enquanto tal — e o pensamento - mostra-se aí independente da sanção de qualquer indivíduo particular, quer dizer, ela não é propriedade de ninguém (Lefort, 1983, pp. 54-55). A originalidade política da democracia é assim designada por este duplo fenômeno: um poder destinado a permanecer

3 Sobre o assunto, cf. Flynn, 2008, Parte 4. 
em busca de seu fundamento, porque perdeu a garantia da imagem da unidade, e uma sociedade que acolhe o conflito de opiniōes e a luta por direitos, porque se dissolveram os marcos de referência da certeza que permitiam aos homens, no Antigo Regime, situarem-se de uma maneira fixa, e que os impede, no regime totalitário, de resistir à incorporação pelo Estado (Ibid., p. I20).

Mas não só isso. Toda Cidade, toda comunidade política, ensina Maquiavel, é atravessada pelo conflito entre os grandes, ou os que desejam dominar, e o povo, isto é, os que desejam não ser dominados. Pensador da liberdade ligada ao funcionamento do desejo no interior do campo político, o florentino defende que a liberdade de todos depende da força do desejo de não dominação para resistir à investida dos grandes. ${ }^{4}$ Ora, ao atribuir aos grandes um desejo insaciável de dominação, Maquiavel dissolve a associação entre nobreza e moderação, feita por aqueles que argumentavam em favor do governo aristocrático e por isso sustentavam a ideia de que quem tem mais se contenta com aquilo que tem, ao passo que o povo seria incapaz de moderação, o que obrigaria o poder à tarefa de frear-lhe constantemente o apetite. Entra em jogo aqui não apenas o questionamento das virtudes atribuídas à nobreza, mas também a rejeição da representação tradicional do povo, cujo comportamento volúvel e anárquico seria determinado pelo desejo de prazer - o que o tornaria fonte de tumulto na Cidade —, para apresentá-lo como o verdadeiro promotor de leis e de instituiçóes aptas a salvaguardar a liberdade política. Assim, ciente da divisão entre os dois humores que atravessam a Cidade, o governo equilibrado deve lidar com o desejo insaciável dos grandes, deixando aflorar o contrapeso que, ao desejo de dominação destes, opõe o desmedido desejo de liberdade do povo.

Lefort mostra, assim, que a obra de Maquiavel se constrói a partir de uma reflexão sobre o papel da indeterminação e do conflito no interior da experiência política. A defesa do caráter negativo do desejo de liberdade - desejo que se caracteriza pela recusa à opressão, e que, de fato, não pode ocupar o poder - e a ideia segundo a qual a ordem instituída no horizonte da Cidade livre não abole o conflito entre os dois humores exigem, ambos, o abandono da imagem da boa sociedade e do bom governo. Uma vez que não há comunidade livre e, ao mesmo tempo, transparente, absolutamente virtuosa e sem conflitos, desfaz-se a possiblidade de que esta produza uma imagem acabada de si mesma. Por um lado, uma vez que é atravessada pelo conflito e dinamizada pelo movimento de resistência à opressão, a comunidade tem de lidar com sua própria indeterminação. Essa desincorporação é trazida à tona quando a força do número - expressa pela exigência do sufrágio universal enquanto direito - se transformar numa das

4 A respeito, cf. Cardoso, 2015. 
marcas instituintes da democracia moderna. Por outro lado, o fenômeno do poder permanece sem o respaldo de uma boa figura, pretensamente definitiva, ancorada na natureza ou na história, uma vez que a dinâmica do desejo de liberdade resiste à tentativa daqueles que pretendem incorporá-lo de maneira absolutamente fundada. O poder permanece sem fundamento e só encontra respaldo contingente no jogo das aparências, das opiniōes e das lutas, com os quais tem de dialogar. Nestes termos, podemos dizer que o campo simbólico não extirpa a circulação de imagens, tampouco o jogo dos afetos e dos apetites do campo político. Pelo contrário, o caráter vazio do lugar do poder dá azo ao circuito das opiniōes, dos afetos e das imagens. Afinal, a apatia política está ligada à denegação dos conflitos e das lutas: a quietude é resultado de uma dominação eficaz a qual, segundo as análises do totalitarismo, se alimenta do fantasma do corpo político despedaçado e do medo que essa fantasia provoca (Lefort, I983, p. II3).

\section{Ordem e desordem}

A democracia, porém, não pode ser lida apenas segundo suas instituições e segundo os direitos que ela pretende garantir sob a forma cristalizada das leis, pois abarca uma experiência selvagem de liberdade: há momentos em que não se pode simplesmente manter as instituições intactas, aquém dos desafios trazidos pelo desmedido desejo de liberdade. Assim, embora explicitada pela defesa da liberdade de opinião e pela exigência do sufrágio universal, por exemplo, a democracia não é redutível às eleições, às instituições ou às leis positivas. Sua pintura tem de recobrir aquilo que nela é da ordem da invisibilidade, algo que a sustenta e a ameaça, a desordem que a perpassa e que não pode ser completamente abolida. Maio de 68 é revelador nesse sentido, pois mostra que a dinâmica democrática pode dar lugar à suspensão temporária da Lei, ou dos laços simbólicos que de certo modo mantêm coesa a sociedade, assim como à consequente experiência da paixão revolucionária, surgida num momento em que não há mais tão-somente uma cabeça do poder a ser decepada, mas sim várias figuras da autoridade.

Em Maio de 68, o surgimento da figura política do estudante e a aliança deste com os trabalhadores são marcas de um novo estilo de luta que exige decifração e leitura. Os estudantes não são uma classe, tampouco configuram uma vanguarda, no sentido tradicional. Atores inesperados, eles não agem segundo os ditames estipulados pela militância dos partidos e dos sindicatos. A despeito disso, a ação destes aparece aos trabalhadores como imitável: "bastaram alguns dias para que se rasgasse o mito da racionalidade do sistema presente e da legitimidade dos detentores do poder" (Lefort, 2008, p. 57). Doravante, salienta Lefort, o poder não está mais ao abrigo da revolução, o poder está nu, pois, ao descobrir-se infundado, suspenso em sua legitimidade, ele tem de remontar à sua fonte de legitimação, 
inconstante, porque sempre passível de desconfiar do poder e, no limite, imprevisível: a própria sociedade ou o povo que a ele se submete.

É verdade que essa não foi a primeira vez que o poder se viu nu. Muito menos na França, lugar de tradição revolucionária. Porém, a maneira como essa nudez se produz é nova: um estilo de ação se impõe quando os agitadores impedem momentaneamente o funcionamento de certos mecanismos a tal ponto que, por um momento "o consenso desmorona" (Ibid.). Essa ação fez minar a adesão inconsciente dos estudantes e dos professores ao que organizava a realidade da vida quotidiana. Quando, mais tarde, lançados na rua pela agressão policial na Sorbonne, os estudantes arrancam e atiram os paralelepípedos, encontram nesse gesto o equivalente do que haviam feito na universidade. Do mesmo modo, a barricada não tem apenas a função de muro de proteção apto para assegurar a resposta aos agressores, ela é um símbolo de ruptura da ordem, a instituição de uma nova desordem. Os estudantes agem à margem do âmbito das organizações estabelecidas e nisso atacam o ponto nevrálgico que organiza a vida na sociedade burguesa: a burocratização de todas as atividades, especialmente da ação, reiteradamente apartada do exercício pensamento. Assim, o desmedido desejo de liberdade se expressa de maneira inesperada, expóe antigas mazelas, confronta seus males. Não foi um mal localizado que se tornou evidente à vista de todos - o mal de uma Universidade presa a práticas arcaicas ou o mal de um poder que maneja de maneira atrapalhada a violência policial de que dispóe. A Universidade foi o palco de uma implosão temporária das estruturas de opressão que permeavam o tecido social. Para realizar essa ação, porém, a sociedade teve de se expor, de maneira radical, no seu próprio movimento de desintegração enquanto corpo.

Por um lado, ao tocarem em suas próprias feridas, os furiosos de Nanterre trouxeram à visibilidade um mal antes vivido de maneira difusa. Mal estruturado segundo a divisão hierárquica entre os que mandam e os que obedecem, entre os que sabem e os que não sabem, entre os que pensam e os que simplesmente agem. Os estudantes, por sua ação de suspensão de certos interditos, desvelaram a figura irracional da Lei e a alienação do saber e da ação quotidianos. Porém, por outro lado, essa suspensão guarda uma ambiguidade capaz de pôr em risco a própria instituição democrática. Há perigo em desfazer o laço simbólico que une os homens em sociedade, pois a ruptura da Lei pode gerar o afeto político mais nocivo de todos: o desprezo que, aliado ao temor, pode gerar o pior dos apetites, o anseio por uma ordem autoritária.

Vejamos. Por um lado, o conflito entre o desejo dos grandes e o desejo de liberdade dinamiza a vida democrática, pois exige respostas criativas por parte das instituiçóes e das leis. Trata-se de um conflito que abarca inclusive o extraordinário - palavra recorrente nos textos de Lefort sobre Maio de 68 -, isto é, aquilo que 
as leis positivas e as instituições cristalizadas ainda não contemplam ou mesmo preveem. Trata-se também, em alguns casos, de recusar certas leis, de impedir a petrificação destas, no momento em que se tornam ancoragem para o desejo de dominação. É preciso repetir: leis e instituições não são boas em si mesmas, pois

[...] as leis positivas estão expostas aos efeitos da divisão social, isto é, aos conflitos. Abrigados sob as leis estabelecidas, os grandes procuram não somente conservar suas riquezas e poder, mas também adquirir muito mais [...] o desejo de ter é insaciável. Contra esse desejo, o povo faz suas reivindicações; almeja estar em segurança, beneficiar-se de vantagens materiais e, principalmente, não ser oprimido. Somente em razão do temor que o povo inspira é que a minoria se vê coagida à prudência e então podem nascer leis novas favoráveis à concórdia (Lefort, I999, p. I68).

Podemos dizer que, no limite, a luta por direitos toca uma zona de ilegalidade. Decerto, a vida democrática envolve a exigência da mediação da lei e das instituições - afinal, trata-se de evitar a dominação do homem pelo homem. Essa exigência, porém, tem de evitar a hipóstase e a cristalização destas, pois isso poderia redundar num movimento que levaria o desejo de dominação a parasitá-las para então exercer-se sob o seu abrigo. É preciso evitar que as leis positivas e o próprio Direito ocupem o lugar do poder, pois isso poderia fomentar a passagem a uma ordem autoritária. Nos termos de Maquiavel, a licença vem à tona contra o perigo da tirania. Maio de 68 enfrenta este perigo de forma radical, pois suspende não apenas a vigência das leis empíricas e o funcionamento das instituições, mas sim a Lei, ou seja, toda a ordem simbólica que estrutura a vida social.

Por outro lado, se a ordem não é boa em si mesma, tampouco a licença ou a desordem o é. Quando o poder aparece ao mesmo tempo vazio e nu, perde-se a vigência do campo simbólico de tal modo que se abre a possibilidade de um movimento abrupto de queda no real. Assim, os representantes do poder aparecem segundo sua mera realidade empírica (ladrōes, corruptos, gangues), sem o respaldo do lugar simbólico que ocupam. Despidos, eles suscitam o desprezo, de modo que os ataques que sofrem são o sinal de que a estrutura de relações conflitivas que sustenta a vida democrática sofre o perigo de degradar-se no limite da fratura. Ao analisar Maio de 68, Lefort lembra que o ataque à autoridade confundia muitas vezes o questionamento das funções, e da legitimidade de seu exercício segundo certas regras, com o questionamento moral de seus ocupantes. Essa ambiguidade aponta para o risco de se passar do desejo de liberdade ao desprezo pelo campo simbólico que poderia mediá-lo em sua ação política. Trata-se de uma prova de fogo para a democracia, pois esta deve ser forte o suficiente para lidar com o grau 
máximo da indeterminação, quando todo o quadro de referência para a ação e o juízo encontra-se momentaneamente suspenso.

Ora, segundo Lefort, o totalitarismo deriva de uma mutação simbólica no interior do regime democrático. Mutação que estabelece uma rota de fuga tendo em vista a visão do corpo político ameaçado pelo despedaçamento, pois nasce da impossibilidade de lidar com a indeterminação, característica da democracia, por considerá-la desprezível do ponto de vista da tarefa de manutenção da ordem. O temor da desordem incita o medo em relação ao povo, fruto da fantasia produzida em torno de suas divisões e de sua inconstância. A enigmática associação entre democracia e totalitarismo, considerando-se que o segundo é uma mutação simbólica da primeira, de algum modo se esclarece:

Poder político [...] exposto à ameaça de cair no abismo da particularidade, de excitar o que Maquiavel julgava mais perigoso que o ódio, o desprezo; como aqueles que o exercem ou a ele aspiram estão expostos à ameaça de tomar figura de indivíduos ou bandos simplesmente ocupados em satisfazer seus apetites. Com o totalitarismo instala-se um dispositivo que tende a exorcizar essa ameaça, que tende a soldar novamente o poder e a sociedade, a apagar todos os sinais da divisão social, a banir a indeterminação que persegue a experiência democrática (Lefort, 1983, p. I20).

É o temor em relação ao povo que desfigura o desejo de liberdade, que o cala em nome da ordem. Esse afeto aparece no campo político, segundo a linguagem de Maquiavel, como uma espécie de termômetro que vai da licença à tirania. Entre esses dois extremos, localiza-se a liberdade política sob a vigência dinâmica das leis e das instituiçôes. Por um lado, é necessário que os grandes temam o povo, pois só assim o desejo de dominação pode ser moderado pelo desejo de liberdade. Por outro lado, a ameaça de um completo despedaçamento do corpo político pode gerar o desprezo pela estrutura simbólica que permite a experiência democrática e, por consequência, sua mutação em autoritarismo e, no limite, em totalitarismo.

Equilíbrio difícil, experiência trágica de uma fratura que não pode ser saturada, de um conflito que não pode se resolver definitivamente, de uma indeterminação que precisa se reiterar sem cessar, sob o risco de pôr por terra a esperança de uma vida livre. Se, a partir de Maio de 68, "a revolução amadureceu" (Lefort, 2008, p. 8I), isso só pode significar que, no interior da democracia, as lutas mais fecundas são aquelas mobilizadas pelo desejo de liberdade, desejo desmedido e sem objeto, é verdade, mas que, ao mesmo tempo, corre o risco de se transmutar num medo determinado e obsessivo, o medo em relação ao próprio povo; ou à fratura da sociedade ou do corpo político. 
O equilíbrio instável, entre a licença e a tirania, que fomenta a liberdade, não pode, nem deve extirpar completamente o medo, pois é necessário, em certa medida, que os grandes temam o desejo de liberdade. Um povo apático não pode ser livre, uma Cidade sem tumultos sofre calada a investida dos grandes. Talvez nenhuma passagem expresse melhor o vigor de um povo que respeita, de maneira vigilante, a vida sob as leis e as instituições do que essa, escrita por Espinosa:

Se numa Cidade os cidadãos não tomam das armas porque estão aterrados pelo medo, não se pode dizer que aí exista paz e sim mera ausência de guerra. A paz não é pura ausência de guerra, mas virtude originada da força d'alma no respeito às leis [...]. Uma Cidade onde a paz é efeito da inércia dos súditos tangidos como rebanho e feitos apenas para servir merece antes o nome de solidão do que de Cidade (Espinosa apud Chaui, 1987, p. 56).

Um povo livre respeita as leis, mas armado. Dividido entre o abrigo da lei e a desconfiança em relação ao potencial opressor desta, ele só pode ter uma experiência trágica da liberdade, só pode vivê-la como uma questão que nunca se fecha, como um anseio que jamais encontra um objeto que possa saciá-lo. A política, ensina Maquiavel, tem algo da arte da guerra. A luta pela liberdade não pode se enganar a respeito do verdadeiro inimigo a ser combatido, aquilo que um povo livre deve de fato recusar, isto é, a opressão. Para Lefort, esse inimigo não é, portanto, a democracia enquanto tal e, por isso, sua escrita, seja quando lê os autores do passado seja quando se volta para o enigma da Modernidade, assume o compromisso de sustentar a questão democrática e com ela o vigor do desejo de liberdade.

\section{Referências}

Adverse, Helton (2009). Maquiavel. Política e retórica, Belo Horizonte: Editora da UFMG.

CARdoso, Sérgio (2015). "Em direção ao núcleo da 'obra Maquiavel': sobre a divisão civil e suas interpretações", Discurso, v. 45, n. 2, pp. 207-248.

Chaur, Marilena (1987), "Sobre o medo", In Adauto Novaes (Org.), Os sentidos da paixão, São Paulo: Companhia das Letras, pp. 35-76.

Flynn, Bernard (2008). Lefort y lo político, Buenos Aires: Prometeo Libros.

Lefort, Claude (1972). Le travail de l'oeuvre Machiavel, Paris: Éditions Gallimard.

LEForT, Claude (1978). Sur une colonne absente. Écrits autor de Merleau-Ponty, Paris, Gallimard. 
Lefort, Claude (1983). A Invenção democrática: os limites da dominação totalitária. São Paulo: Brasiliense.

Lefort, Claude (199I). Pensando o político: ensaios sobre democracia, revolução e liberdade. Rio de Janeiro: Paz e Terra.

Lefort, Claude (1999). Desafios da Escrita Política. São Paulo: Discurso Editorial.

Morin, Edgar; Lefort, Claude.; Coudray, Jean-Marc (2008). Mai 1968: La Brèche suivi de Vingt ans après. Paris: Libraire Arthème Fayard.

Poltier, Hughes (1997). La découverte du politique, Paris: Éditions Michalon. 